\title{
COMPOSIÇÃO FLORÍSTICA DA VEGETAÇÃO ARBÓREA DE UM TRECHO DE FLORESTA ESTACIONAL SEMIDECÍDUA EM VIÇOSA, MINAS GERAIS, E ESPÉCIES DE MAIOR OCORRÊNCIA NA REGIÃO ${ }^{1}$
}

\author{
Walnir Gomes Ferreira Júnior², Alexandre Francisco da Silva³, João Augusto Alves Meira Neto³, Carlos \\ Ernesto Gonçalves Reynaud Schaefer ${ }^{4}$, Arildo de Souza Dias ${ }^{5}$, Maíra Ignácio ${ }^{5}$ e Maria Cláudia Melo \\ Pacheco de Medeiros $^{6}$
}

\begin{abstract}
RESUMO -É grande a demanda por estudos ecológicos em florestas que possam embasar trabalhos de recuperação, conservação da biodiversidade e apoio à legislação ambiental. Entre esses estudos, primordialmente está o levantamento da flora. Nesse sentido, este trabalho teve como objetivo determinar a composição florística de um trecho da Reserva da Biologia, em Viçosa, MG, em regeneração natural há 80 anos, bem como realizar uma análise comparativa com outros trabalhos conduzidos na região, fornecendo, assim, informações que poderão embasar estudos sobre recuperação e conservação da biodiversidade dos fragmentos de Floresta Estacional Semidecidual. Os dados florísticos foram obtidos mediante a amostragem fitossociológica em 1 ha, pelo método de parcelas contíguas, em que todos os indivíduos arbóreos com circunferência de tronco $\geq 15 \mathrm{~cm}$ a $1,30 \mathrm{~m}$ do solo foram amostrados. Registraram-se 130 espécies, distribuídas em 94 gêneros, pertencentes a 38 famílias botânicas. A análise desses dados conjuntamente com de outros levantamentos realizados em trechos distintos da Reserva da Biologia, no campus da UFV, denota a marcante influência de variáveis ambientais locais (topografia, declividade, face de exposição solar e disponibilidade hídrica) na distribuição da riqueza florística desse fragmento. Casearia decandra, Guapira opposita, Apuleia leiocarpa, Dalbergia nigra, Jacaranda macratha, Matayba elaeagnoides, Piptadenia gonoacantha, Bathysa nicholsonii, Carpotroche brasiliensis, Luehea grandiflora, Mabea fistulifera, Ocotea odorifera, Sorocea bonplandii e Zanthoxylum rhoifolium foram as espécies de maior ocorrência nos fragmentos estudados na região de Viçosa e adjacências, apresentando potencial para uso na recuperação florestal de áreas degradadas.
\end{abstract}

Palavras-chave: Floresta Estacional Semidecidual, fragmentação florestal e recuperação de áreas degradadas.

\section{FLORISTIC COMPOSITION OF TREES IN A SEASONAL SEMIDECIDUOUS FOREST IN VIÇOSA, MINAS GERAIS, AND SPECIES OF GREATER OCCURRENCE IN THE REGION}

\begin{abstract}
There is a great demand for ecological studies on forests focusing on biodiversity conservation and establishment of environmental laws. The major need, however, is the qualitative survey of the flora. Thus, this work aimed to determine the floristic composition of a site in the Biological Reserve of the Federal University of Viçosa (UFV) in Vicosa-MG, under natural regeneration for 78 years, as well as to establish a comparative analysis with other works in the region, providing information to serve as a basis for further
\end{abstract}

\footnotetext{
${ }^{1}$ Recebido em 21.10.2006 e aceito para publicação em 05.04.2007.

${ }^{2}$ Programa de Pós-Graduação em Biologia Vegetal da Universidade Federal de Viçosa (UFV). E-mail: <wjr@ vicosa.ufv.br>.

${ }^{3}$ Departamento de Biologia Vegetal da UFV. E-mail: <j.meira@ufv.br>.

${ }^{4}$ Departamento de Solos da UFV. E-mail: <carlos.schaefer@ufv.br>.

${ }^{5}$ Programa de Pós-Graduação em Botânica da UFV. E-mail: <arildosouzadias @ yahoo.com.br>.

${ }^{6}$ ProgramadePós-GraduaçãoemBiodiversidade VegetaleMeioAmbientedoInstitutodeBotância,SãoPaulo-SP.E-mail:<mclaudia82@yahoo.com.br>.
} 


\begin{abstract}
works on recovery and conservation of the biodiversity of seasonal semi deciduous forest sites. The floristic data were obtained by phytosociological sampling in 1 ha, through contiguous plots, with all the wood individuals with stem diameter $=4.7 \mathrm{~cm}, 1.30 \mathrm{~m}$ far from the soil were recorded. A total of 130 species was sampled, belonging to 94 genera and 38 botanical families. The analysis of those data combined with other surveys in different sites of the Biological Reserve on the UFV campus showed a remarkable influence of local environmental variables (topography, slopes, sun exposure and water availability on the floristic richness distribution of this site. Casearia decandra, Guapira opposita, Apuleia leiocarpa, Dalbergia nigra, Jacaranda macratha, Matayba elaeagnoides, Piptadenia gonoacantha, Bathysa nicholsonii, Carpotroche brasiliensis, Luehea grandiflora, Mabea fistulifera, Ocotea odorifera, Sorocea bonplandii and Zanthoxylum rhoifolium presented the highest occurrence in the sites studied in the Viçosa region and are recommended for recovery of degraded environments in regions.
\end{abstract}

Keywords: Seasonal semi deciduous forest, forest fragmentation and recovery of degraded areas.

\section{INTRODUÇÃO}

A Floresta Estacional Semidecídua recobria extensas áreas de Minas Gerais, estabelecendo no passado um continuum com a floresta do médio Paraíba (VALVERDE, 1958), que, segundo Aubréville (1959), estendia-se desde o litoral do Estado do Espírito Santo até as cercanias da cidade de Belo Horizonte, passando pelo vale do Rio Doce, ao norte. Atualmente, essa vegetação outrora exuberante encontra-se "ilhada" nas áreas de declividade acentuada e, ou, impróprias para o cultivo, na forma de inúmeros fragmentos (SILVA et al., 2003), com vários formatos e tamanhos ou preservada das intervenções antrópicas nas unidades de conservação.

Ao longo de toda extensão da Mata Atlântica, o processo de fragmentação da vegetação, iniciado há muitas décadas (DEAN, 1996), tem levado, certamente, a uma significativa perda da biodiversidade, que nem sequer chegou a conhecer (ALMEIDA e SOUZA, 1997). Os fragmentos florestais remanescentes, de diferentes tamanhos, formas, graus de isolamento, tipos de vizinhança e históricos de perturbações, estão comprometidos em sua composição, estrutura e dinâmica, sendo a perda de biodiversidade o principal impacto ambiental do processo de isolamento (NASCIMENTO et al., 1999; BRASIL, 2003), além da alteração do regime hídrico das bacias hidrográficas a das condições climáticas (VIANA et al., 1992).

Tais fragmentos florestais, segundo Whitmore (1978), representam um mosaico de manchas em distintos estados de conservação e sucessão, sendo, portanto, necessário reconstituir ao máximo a história da vegetação local e, se possível, efetuar comparações entre fragmentos de diferentes áreas remanescentes da mesma cobertura original, para melhor entendimento da sua composição florística, estrutura e dinâmica. Desse modo, dados ecológicos importantes acerca das comunidades nesses locais poderão ser conhecidos, fornecendo, assim, subsídios necessários ao desenvolvimento de planos de recuperação de áreas degradadas, restauração ambiental e de manejo e conservação de espécies.

Atualmente, alguns estudos de cunho investigativo da flora arbórea das Florestas Semidecíduas da região foram realizados (ALMEIDA e SOUZA, 1997; MEIRANETO et al., 1997; SILVA et al., 2000; WERNECK et al., 2000; LOPES et al., 2002 a,b; MEIRA-NETO et al., 2002; MARANGON et al., 2003; SILVAet al., 2003; RIBAS et al., 2003; MEYER et al., 2004; SILVA et al., 2004; CAMPOS et al., 2006; SOARES et al., 2006; FERREIRAJÚNIOR et al., 2007) e são enfáticos em ressaltar a considerável riqueza de espécies nos remanescentes estudados. Estudos ecológicos acerca dos outros compartimentos do ecossistema e de aspectos sinecológicos das Florestas Estacionais Semidecíduas também foram realizados. Meira-Neto et al. (2000) e Silva-Júnior et al. (2004) avaliaram a composição florística do estrato herbáceo-arbustivo; Martins et al. (2003), Meira-Neto et al. (2005), Carvalho et al. (2005a,b), Rodrigues et al. (2007) e Ferreira-Júnior et al. (2007) apontaram a grande heterogeneidade ambiental relacionada ao gradiente pedológico e topográfico como um dos principais fatores atuando na organização florística e estrutural dessas florestas; Pezzopane et al. (2002) estudaram aspectos ecofisiológicos de algumas espécies arbóreas em regeneração natural; e Werneck et al. (2001) e Dias et al. (2002) avaliaram a produção e a variação temporal de nutrientes na serrapilheira.

R. Árvore, Viçosa-MG, v.31, n.6, p.1121-1130, 2007 
A região de Viçosa destaca-se pela existência de muitos remanescentes de Floresta Estacional Semidecídua, sendo os situados no interior do campus da Universidade Federal de Viçosa (UFV) parcialmente protegidos das intervenções antrópicas há 80 anos. Portanto, este trabalho teve como objetivos determinar a composição florística de um trecho da Floresta Estacional Semidecídua localizada no campus da UFV em sucessão ecológica secundária há 80 anos e identificar as espécies florestais arbóreas de maior ocorrência nos fragmentos da região.

\section{MATERIAIS E MÉTODOS}

\section{1. Área de estudo}

O Município de Viçosa faz parte das Terras Altas Brasileiras, numa divisão geopolítica denominada Zona da Mata do Estado de Minas Gerais (Figura 1) (CARNEIRO e FONTES, 2005). De acordo com Veloso et al. (1991), é parte integrante do domínio da Floresta Estacional Semidecidual, dentro do ecossistema denominado Floresta Tropical Atlântica ou Mata Atlântica, constituindo uma formação intermediária entre as formações florestais perenes da encosta e as formações não-florestais do interior.

O Município de Viçosa, 2045'14”S e 4245’53”O (Figura 1) e altitude variando de 620 a 820 m, situase perifericamente no norte da Zona da Mata, entrecortado por rios e córregos tributários do rio Doce, apresentando relevo de fortemente ondulado a montanhoso (VALVERDE, 1958). Apresenta predominância de duas classes de solo, estando o Latossolo Vermelho-Amarelo álico no topo das elevações e encostas, enquanto o Argissolo Vermelho-Amarelo Câmbico domina as feições do relevo denominadas terraços fluviais (RESENDE et al., 1988). Informações acerca das classes de solos, dos gradientes pedológico e topográfico e da influência destes sobre a distribuição espacial de algumas populações arbóreas da área de estudo estão em FerreiraJúnior et al. (2007). O clima da região é classificado como tropical de altitude com verões chuvosos e invernos frios e secos (Cwb) (BRASIL, 1992). De acordo com Castro et al. (1973), a média anual da umidade relativa e da temperatura do ar fica em torno de $80 \%$ e $19{ }^{\circ} \mathrm{C}$, respectivamente, sendo a média das máximas $21,6^{\circ} \mathrm{C}$ e das mínimas $14^{\circ} \mathrm{C}$. A precipitação média anual é de $1.340 \mathrm{~mm}$.

O estudo foi realizado em um remanescente florestal localizado no campus da Universidade Federal de Viçosa, conhecido como Reserva da Biologia (Figura 1). Esta, com aproximados 75 ha, encontra-se atualmente em processo de regeneração natural, iniciado em 1926, logo após a aquisição da área, antes cultivada com café, pela então Escola Superior de Agricultura e Veterinária (ESAV). Desde então, a referida área encontrase parcialmente protegida de cortes e extração de madeira.

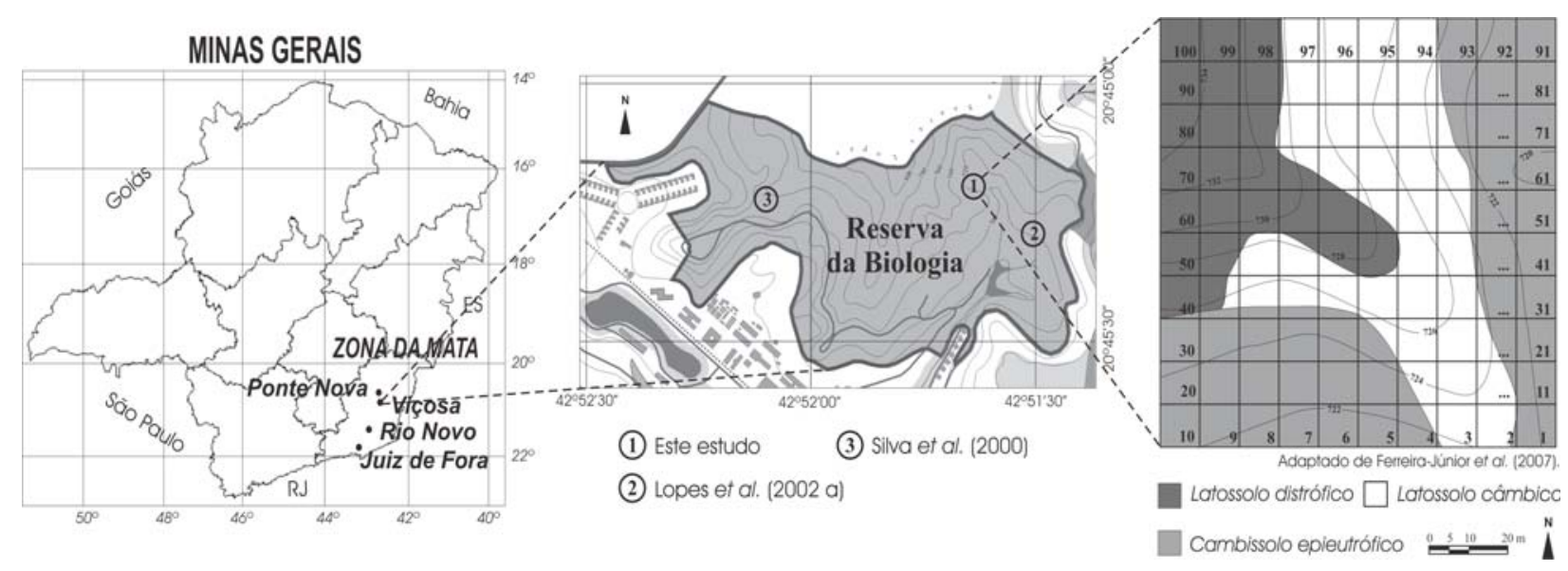

Figura 1 - Mapa da localização dos estudos utilizados na análise de similaridade florística, da área de amostra e da disposição das parcelas do levantamento fitossociológico na Reserva da Biologia, campus da Universidade Federal de Viçosa, em Viçosa, Minas Gerais, Brasil.

Figure 1 -Map showing the location of the areas used in the floristic similarity analysis and plots of the phytosociological survey at the Biological Reserve on the UFV campus. 


\subsection{Composição florística}

A listagem florística foi elaborada a partir de uma amostra fitossociológica com área de 1 ha, tendo sido utilizado o método de parcelas contíguas, proposto por Mueller-Dombois e Ellenberg (1974), em que foram alocadas 100 parcelas com dimensões de 10 x $10 \mathrm{~m}$, totalizando 1,0 ha (Figura 1). Nestas, todos os indivíduos arbóreos, vivos ou mortos em pé, com circunferência de tronco a $130 \mathrm{~cm}$ do solo (CAP), igual ou superior a $15 \mathrm{~cm}$, foram amostrados. A identificação taxonômica foi realizada por meio de literatura especializada, mediante consulta ao Herbário do Departamento de Biologia Vegetal da Universidade Federal de Viçosa (VIC), onde foi depositado o material-testemunho e, nos grupos mais complexos, foram consultados especialistas.

Para organização da listagem florística, foi adotado o sistema de classificação de Cronquist (1981), exceto para a família Leguminosae, onde se optou pelo sistema de Engler (três subfamílias). Todos os nomes de espécies e respectivos autores foram confirmados e atualizados pelo "software" do índice de espécies do Royal Botanical Gardens of Kew (1997).

\subsection{Espécies de maior ocorrência na região}

Para realização da análise comparativa da composição florística, a fim de identificar as espécies mais freqüentemente amostradas na Zona da Mata do Estado de Minas Gerais (Figura 1), foram utilizadas as listagens florísticas de 14 estudos, além da lista florística deste trabalho: Senra (2000), Silva et al. (2000), Soares Júnior (2000), Irsigler (2002), Lopes et al. (2002a), Meira-Neto et al. (2002), Marangon et al. (2003), Ribas et al. (2003), Silva et al. (2003), Silva et al. (2004) e Campos (2006), em Viçosa; Almeida e Souza (1997), em Juiz de Fora; Meira-Neto et al. (1997), em Ponte Nova; e Silva (dados não publicados), em Rio Novo.

Foram calculados os índices de similaridade de Sørensen (MUELLER-DOMBOIS e ELLENBERG, 1974), entre o presente estudo e outros realizados em diferentes municípios da Zona da Mata de Minas Gerais, mediante o uso da seguinte expressão: $I S=(2 C / A+B) * 100$; em que $\mathrm{C}=$ número de espécies comuns às duas comunidades confrontadas; $\mathrm{A}=$ número total de espécies na comunidade $\mathrm{A}$; e $\mathrm{B}=$ número total de espécies na comunidade $\mathrm{B}$.

R. Árvore, Viçosa-MG, v.31, n.6, p.1121-1130, 2007

\section{RESULTADOS E DISCUSSÃO}

No levantamento desta pesquisa foram relacionadas 130 espécies arbóreas pertencentes a 94 gêneros e 38 famílias botânicas, conforme a Tabela 1 . Entre as espécies, seis tiveram a identificação mais exclusiva possível em nível de gênero e uma no nível de família.

Tabela 1 - Lista das espécies arbóreas amostradas em um trecho de Floresta Estacional Semicedídua, na Reserva da Biologia, face predominante sudeste, no campus da Universidade Federal de Viçosa, Minas Gerais

Table 1 - Tree species sampled in a site of semideciduous seasonal forest at the Biological Reserve, on the UFV campus

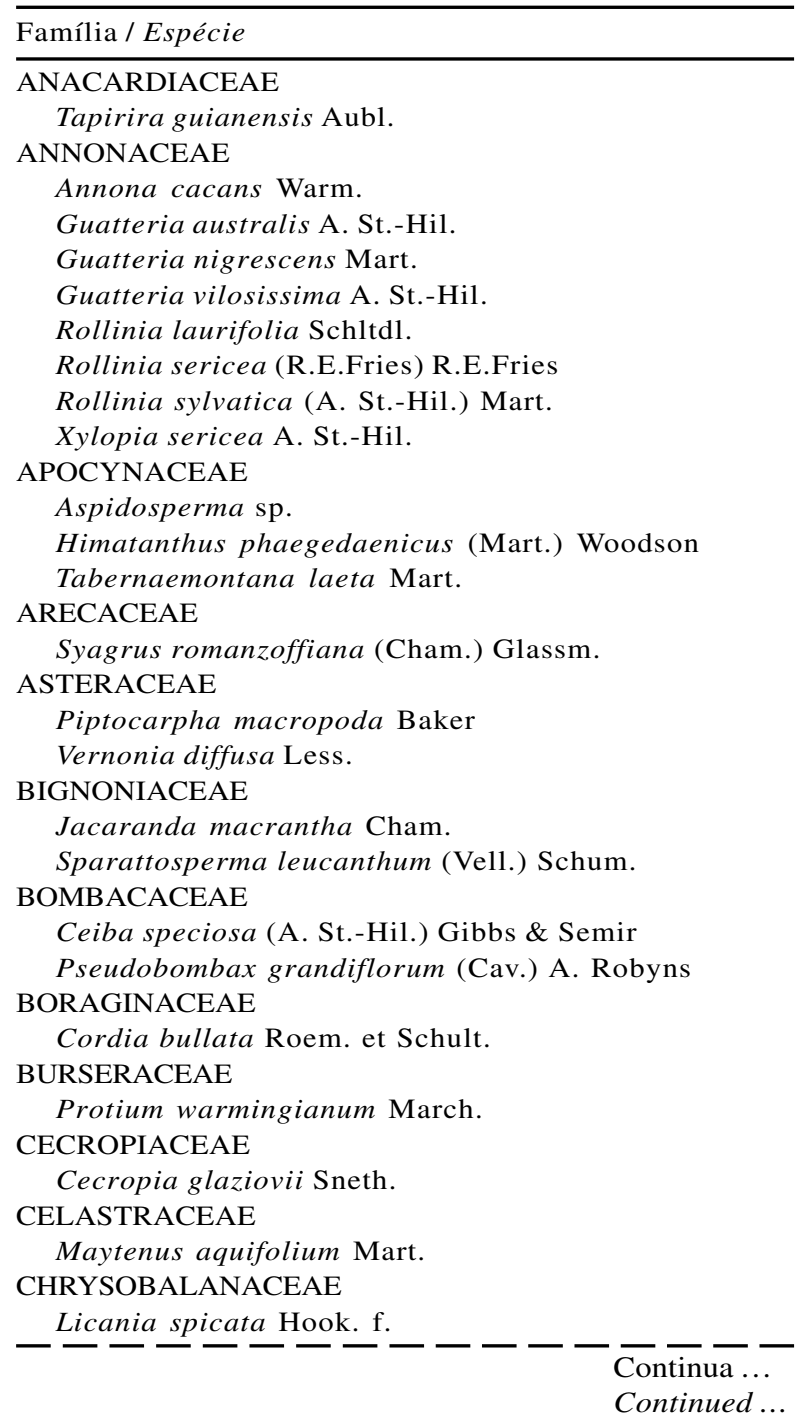


Tabela 1 - Cont

Table 1 - Cont.

Família/Espécie

ERYTHROXYLACEAE

Erythroxylum pelleterianum A. St.-Hil.

EUPHORBIACEAE

Alchornea glandulosa Poepp. \& Engl.

Croton floribundus Spreng.

Mabea fistulifera Mart.

Sapium glandulatum Pax

FLACOURTIACEAE

Carpotroche brasiliensis (Raddi) Endl.

Casearia arborea Urb.

Casearia decandra Jacq.

Casearia gossypiosperma Briq.

Casearia sylvestris $\mathrm{Sw}$.

Casearia ulmifolia Vahl ex Vent.

Xylosma salzmannii (Clos) Eichler

GUTTIFERAE

Rheedia gardneriana $\mathrm{Pl}$. et $\mathrm{Tr}$.

CACINACEAE

Citronella megaphylla (Miers) Howard

Citronella paniculata (Mart.) Howard.

LACISTEMATACEAE

Lacistema pubescens Mart.

LAURACEAE

Aniba firmula Mez.

Cryptocarya moschata Nees \& C. Mart.

Cryptocarya sp.

Endlicheria paniculata (Spreng.) Macbride

Lauraceae sp. 1

Nectandra lanceolata Ness \& Mart. ex Ness

Nectandra rigida Ness

Ocotea dispersa $\mathrm{Mez}$

Ocotea odorifera (Vell.) J.G.Rohwer

Ocotea sp.

Ocotea teleiandra (Meisn.) Mez

Persea pyrifolia Ness

LECYTHIDACEAE

Cariniana estrellensis Kuntze

Cariniana legalis Kuntze

LEGUMINOSAE

Acacia glomerosa Benth.

Albizia polycephala (Benth.) Killip

Anadenanthera colubrina (Benth.) Brenan

Anadenanthera peregrina (L.) Speg.

Apuleia leiocarpa Macbride

Bauhinia forficata Link

Cassia ferruginea Schrad. ex. DC.

Copaifera langsdorffii Desf.

Dalbergia nigra Allem. ex Benth.

Inga affinis DC.

Inga marginata Wild.

Machaerium brasiliense Vog.

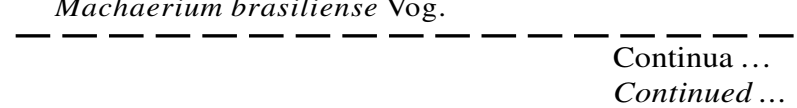

Tabela 1 - Cont.

Table 1 - Cont.

Família/Espécie

LEGUMINOSAE

Machaerium floridum (Mart.) Ducke

Machaerium nictitans (Vell.) Benth.

Machaerium stipitatum (DC.) Vogel

Peltophorum dubium Taub.

Piptadenia gonoacantha Macbride

Piptadenia paniculata Benth.

Pithecellobium langsdorffii Benth.

Platymiscium pubescens Micheli

Platypodium elegans Vog.

Pseudopiptadenia contorta (DC.) G.P.Lewis \& M.P.M. de Lima

Senna multijuga (L. C. Rich.) Irwin \& Barneby

Swartzia elegans Schott

MELASTOMATACEAE

Miconia candolleana Naudin

Miconia chamissois Naudin

MELIACEAE

Cabralea canjerana (Vell.) Mart.

Cedrela fissilis Vell.

Guarea kunthiana A. Juss.

Guarea macrophylla Vahl

Trichilia catigua A. Juss.

Trichilia elegans A. Juss.

Trichilia lepidota $\mathrm{Sw}$.

Trichilia pallida $\mathrm{Sw}$.

MONIMIACEAE

Mollinedia schottiana (Spreng.) Perk.

Siparuna guianensis Aubl.

MORACEAE

Acanthinophyllum ilicifolium (Spreng.) Burger

Ficus enormis (Mart. ex Miq.) Miq.

Maclura tinctoria D. Don ex Steud.

Sorocea bonplandii (Baill.) Burger, Lanjow \& Boer

Sorocea guilleminiana Gaudich.

MYRTACEAE

Campomanesia xanthocarpa Berg.

Eugenia leptoclada Berg.

Eugenia sp.

Eugenia sp. 1

Eugenia sp. 2

Eugenia strictosepala Kiaersk.

Marlierea tenscheriana (O. Berg.) D. Legrand.

Myrcia fallax DC.

Myrciaria ciliolata (Cambess.) O. Berg.

Plinia glomerata (Berg.) Amshoff

NYCTAGINACEAE

Guapira hirsuta (Choisy) Lundell

Guapira opposita (Vell.) Reitz.

PHYTOLACCACEAE

$-\underline{\text { Seguieria }} \underline{\text { americana }} \underline{\mathrm{L}}-\underline{-}---\frac{-}{\text { Continua } \ldots}$

R. Árvore, Viçosa-MG, v.31, n.6, p.1121-1130, 2007 
Tabela 1 - Cont.

Table 1 - Cont.

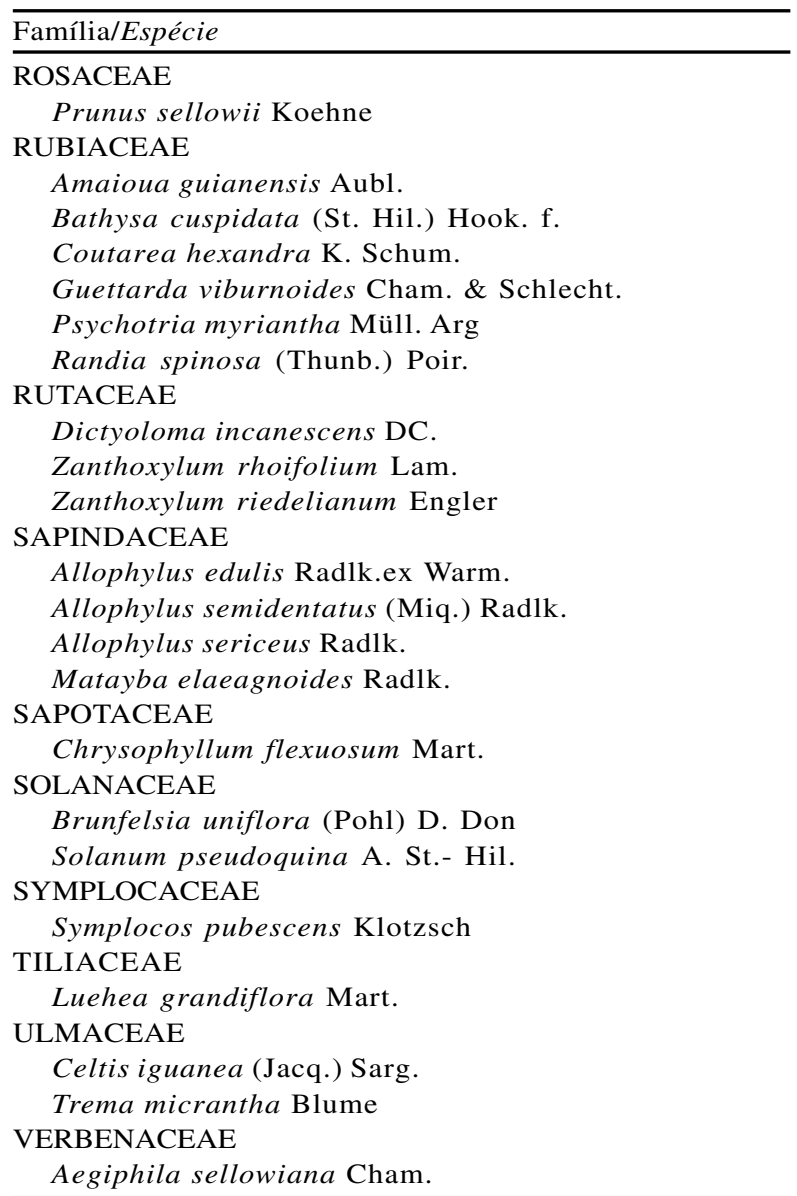

Com as maiores riquezas, destacaram-se os gêneros Casearia e Eugenia, com cinco espécies cada um; Machaerium, Trichilia e Ocotea, com quatro cada; e Allophylus, Guatteria e Rollinia, ambos com três espécies cada. Esses oito gêneros reuniram 31 espécies, representando $23,84 \%$ da riqueza específica. Ressaltase o fato de que apenas nove $(23,68 \%)$ das 38 famílias responderam por $65,5 \%$ das espécies encontradas. São elas: Leguminosae, Lauraceae, Myrtaceae, Annonaceae, Meliaceae, Flacourtiaceae, Rubiaceae, Euphorbiaceae e Moraceae, que, assim, assumem grande importância na fitocenose em questão.

Essas famílias foram citadas por Lopes et al. (2002a) como as famílias de maior riqueza específica nos remanescentes de Floresta Estacional Semidecídua da Zona da Mata Mineira, após estudo comparativo da composição florística de seis fragmentos da região.
A grande importância dessas famílias nas florestas estacionais já havia sido ressaltada por Leitão Filho (1982), e, atualmente, os levantamentos realizados nos domínios dessa formação, em Minas Gerais, têm corroborado essa afirmação.

Meira Neto e Martins (2002), estudando um remanescente florestal (Mata da Silvicultura) no município de Viçosa; Marangon et al. (2003), em trabalho realizado na Reserva Florestal Mata do Paraíso (Mata da Pedreira); Ribas et al. (2003), no sítio Palmital; Silva et al. (2003), em estudo realizado na Fazenda São Geraldo; e Silva et al. (2004) encontraram as famílias Leguminosae, Myrtaceae, Lauraceae, Euphorbiaceae, Rubiaceae, Flacourtiaceae, Annonaceae e Melastomataceae como representantes da maior riqueza específica.

No Município de Lavras, em estudo realizado por Souza et al. (2003) em um remanescente de Floresta Estacional Semidecídua às margens do rio Capivari, essas mesmas famílias foram citadas como as de maior riqueza específica. Fato semelhante foi observado na Estação Ecológica do Tripuí (vegetação de altitude), no Município de Ouro Preto por Werneck et al. (2000). Também Nunes et al. (2003), estudando a diversidade e a composição de guildas da comunidade arbórea de um fragmento de Floresta Semidecídua no Município de Lavras, MG, encontraram as referidas famílias como as de maior riqueza específica. Em Itutinga, MG, van den Berg e Oliveira-Filho (2000), ao analisarem a composição florística e estrutura fitossociológica de uma floresta ripária, detectaram que aquelas famílias também eram as detentoras da maior riqueza de espécies.

A ocorrência das mesmas famílias com elevada riqueza específica nos estudos realizados em remanescentes de Floresta Estacional Semidecídua na porção leste de Minas Gerais demonstra a considerável ligação florística entre as áreas, condicionada pela similaridade de condições ambientais compartilhadas por estas. Esta porção do Estado é caracterizada por uma menor precipitação e temperaturas amenas, quando comparadas com a região das formações Florestais Ombrófilas de Encosta na Serra do Mar nos Estados do Rio de Janeiro e São Paulo, por exemplo. Somase a isso a marcante estacionalidade climática do domínio das Semidecíduas em Minas Gerais, onde existem duas estações bem definidas: uma chuvosa e quente de outubro a março e outra seca e fria de abril a setembro. Ademais, os solos do domínio dos Mares de Morros 
da porção leste de Minas Gerais são, em sua maior parte, profundos e intensamente intemperizados, apresentando, em conseqüência, baixo conteúdo nutricional. Essas famílias, provavelmente, possuem espécies com características que as tornam mais adaptadas às condições ambientais dessa região, como a capacidade de fixação de $\mathrm{N}_{2}$ atmosférico por espécies de Leguminosae, que é a família de maior importância nessas formações semidecíduas (OLIVEIRA-FILHO e FONTES, 2000) e melhor adaptação aos menores índices pluviométricos, como perda das folhas no inverno (caráter decidual).

Dentre as espécies de Leguminosae amostradas neste estudo, algumas são reconhecidas por Faria et al. (1984,1987) como fixadoras de nitrogênioatmosférico. São elas: Albizia polycephala, Dalbergia nigra, Machaerium brasiliense, Machaerium nyctitans, Machaerium stipitatum, Piptadenia gonoacantha, Piptadenia paniculata, Platypodium elegans e Pseudopiptadenia contorta. Provavelmente, o processo de fixação de $\mathrm{N}_{2}$ atmosférico por essas espécies, via associação com Rhizobium, confere a elas maior capacidade adaptativa nos solos oligotróficos com baixo teor de nitrogênio e bem drenados da Zona da Mata mineira, se comparadas com outras que não apresentam tal habilidade, conforme relatado por FerreiraJúnior et al. (2007).

Oliveira-Filho e Fontes (2000), em investigação sobre a similaridade florística da flora arbórea entre as formações florestais da Mata Atlântica no Sudeste do Brasil, examinaram 125 listagens florísticas disponíveis na literatura e puderam detectar que nas 77 áreas de Floresta Estacional Semidecídua estudadas havia a predominância das seguintes famílias: Leguminosae com 354, Myrtaceae com 273, Rubiaceae com 132, Melastomataceae com 102, Mimosaceae com 101, Euphorbiaceae com 98, Caesalpiniaceae com 87, Annonaceae com 65 e Flacourtiaceae com 52. Ainda de acordo com esses autores, os gêneros Eugenia, Miconia, Myrcia e Ocotea seriam os mais característicos dessa formação florestal, apresentando mais de 60 espécies cada um, na compilação realizada.

A ocorrência de espécies exóticas na área de estudo, Eryobotria japonica Lindl., Citrus sp. e Coffea arabica L., está provavelmente relacionada com o histórico de ocupação da área e a ação de dispersores naturais, haja vista que há 78 anos a área era parte de uma fazenda, com plantações de café e pomares, que foram abandonadas após a aquisição pela antiga Escola Superior de Agricultura e Veterinária (ESAV) e muitos de seus indivíduos permaneceram no interior do fragmento em regeneração, atuando como fonte de diásporos para a área. Essa situação hipotética parece mais plausível quando se observou a população de C. arabica, cujos indivíduos se encontram distribuídos na maioria das parcelas amostradas e em alguns sítios com grande densidade populacional, fato esse constatado durante a realização das atividades de campo e corroborado por um estudo realizado na área, o qual verificou que C. arabica apresentou-se como a espécie de maior valor de importância (DIAS et al., 2005).

Da mesma forma, Lopes et al. (2002a) relataram a ocorrência das mesmas espécies exóticas em outro estudo na Reserva da Biologia, evidenciando que a presença destas, principalmente de $C$. arabica L. no estrato regenerante, é uma situação comum ao fragmento. No Estado de São Paulo, Município de Santa Rita do Passa Quatro, no Parque Estadual de Vassununga, Martins (1991) também relatou a presença de indivíduos de $C$. arabica no sub-bosque, destacando a ação de substâncias alelopáticas, liberadas pelos indivíduos dessa espécie que atuariam como inibidores químicos da germinação de sementes de espécies típicas dos estratos superiores encontrados no piso e estrato inferior da floresta.

As conseqüências danosas da competição interespecífica dos indivíduos de $C$. arabica relatadas por Martins (1991) sobre a regeneração natural dos indivíduos dos estratos superiores foram detectadas na área deste estudo, onde foi observado que, das espécies de maior importância na comunidade arbórea, a maior parte encontra-se sem representante ou representada com baixa densidade populacional no compartimento da regeneração natural (DIAS et al., 2005).

A Reserva da Biologia já foi alvo de três estudos de cunho florístico-fitossociológico, realizados em diferentes trechos desse remanescente, tendo sido utilizado em tais levantamentos o método de parcelas contíguas em 1 ha e nível de inclusão de CAP $\geq 15 \mathrm{~cm}$ a 1,3 $\mathrm{m}$ do solo. Entre eles, este trabalho foi o que apresentou maior riqueza específica, com 130 espécies. Silva et al. (2000) encontraram 91 espécies distribuídas em 77 gêneros pertencentes a 37 famílias, e Lopes et al. (2002 a) amostraram 121 espécies alocadas em 89 gêneros e 39 famílias.

R. Árvore, Viçosa-MG, v.31, n.6, p.1121-1130, 2007 
Entre a área desta pesquisa e a de Lopes et al. (2002a), há uma similaridade florística de 62,3\%, sendo este o maior valor observado em meio aos estudos utilizados nesta análise (Tabela 2). Já a área estudada por Silva et al. (2000) apresentou menor similaridade, $52,3 \%$ (Tabela 2), com a área do presente estudo. Dessa forma, fica evidente que, mesmo que a proximidade geográfica entre áreas seja fator importante para que se verifique maior similaridade florística entre diferentes estudos, características fisiográficas, pedológicas e microclimáticas locais apresentam-se como fatores importantes na determinação da composição florística de comunidades.

Nas faces de exposição solar sul/sudeste e sudoeste, foram realizados, respectivamente, este estudo e o de Lopes et al. (2002a). Durante os meses de menor disponibilidade de água no solo (abril a setembro), ambas as faces, além de receberem maior aporte de umidade das frentes frias vindas do sul e, preferencialmente, nelas ocorrer a formação de neblina e geada (Dr. Carlos Ernesto Gonçalves Reynaud Schaefer, comunicação pessoal), ainda recebem menor quantidade de radiação solar, resultando em menores taxas de evapotranspiração, mantendo por mais tempo as reservas de água do solo. Já a área estudada por Silva et al. (2000) está na face oeste de exposição, recebendo durante o ano grandes quantidades de radiação solar, fato esse agravado pela acentuada declividade do trecho, favorecendo, assim, a penetração de luz pelas áreas descontínuas criadas pelo relevo entre os estratos do dossel florestal, reduzindo significativamente o conteúdo de água disponível no solo.

De acordo com Clinebell II et al. (1995), a riqueza de espécies arbóreas nas florestas tropicais está intimamente ligada a cinco gradientes principais, que são: o latitudinal, o de precipitação, o edáfico, o altitudinal e o intercontinental. Desse modo, pode-se considerar que uma das causas da variação no número de espécies dos três levantamentos está relacionada ao fato de cada uma das áreas estudadas na Reserva da Biologia estarem localizadas em diferentes faces de exposição solar. Portanto, essas áreas estão sujeitas a diferentes níveis de ação dos elementos climáticos, como ventos, massas úmidas, quantidade e intensidade de radiação solar, além do efeito proveniente das feições do relevo, como a presença de sítios de menor ou maior declividade. Soma-se a isso a observação de Tabarelli e Mantovani (1999), sobre a relação direta que há entre a riqueza de espécies e a fertilidade do solo e precipitação, sendo, nesta situação, não observada diferenças na riqueza de espécies relacionadas com a precipitação, tendo em vista a grande proximidade entre as áreas supracitadas.

Tabela 2 - Similaridade florística entre um trecho de Floresta Estacional Semicedídua na Reserva da Biologia, campus da Universidade Federal de Viçosa, Viçosa, MG, e algumas florestas semidecíduas da Zona da Mata do Estado de Minas Gerais. $\mathrm{S}=$ riqueza de espécies; $\mathrm{SC}=$ número de espécies comuns; IS = Índice de Similaridade de Sørensen; UFJF = Universidade Federal de Juiz de Fora; U.H.E. = Usina Hidrelétrica; e A.R.Z.M. = Aeroporto Regional da Zona da Mata

Table 2 - Floristic similarity between a sector of seasonal semi deciduous forest in the Biological Reserve, UFV campus, and other semideciduous forests of Zona da Mata of Minas Gerais. $S=$ number of species; $C S=$ number of common species; IS = Sфrensen's Similarity Index; UFJF = Universidade Federal de Juiz de Fora; A.R.Z.M. = Regional Airport of Zona da Mata

\begin{tabular}{|c|c|c|c|c|c|}
\hline Localidade/Município (MG) & Autor(es) & Alitude (m) & $S$ & SC & IS $(\%)$ \\
\hline Campus da UFJF - Juiz de Fora & Almeida e Souza (1997) & $720-930$ & 78 & 27 & 27,7 \\
\hline U.H.E de Pilar - Ponte Nova & Meira-Neto et al. (1997) & 500 & 89 & 49 & 47,3 \\
\hline Fazenda Rancho Fundo - Viçosa & Senra $(2000)$ & 720 & 107 & 48 & 44,7 \\
\hline Reserva da Biologia - Viçosa & Silva et al. (2000) & 700 & 91 & 56 & 52,3 \\
\hline Fazenda Tico-Tico - Viçosa & Soares-Júnior (2000) & 670 & 81 & 37 & 38,5 \\
\hline Sítio Bom Sucesso - Viçosa & Irsigler (2002) & 780 & 195 & 72 & 45,1 \\
\hline Reserva da Biologia - Viçosa & Lopes et al. (2002 a) & 700 & 121 & 76 & 62,3 \\
\hline Mata da Silvicultura - Viçosa & Meira-Neto e Martins (2002) & $670-730$ & 154 & 68 & 52,5 \\
\hline Mata da Pedreira - Viçosa & Marangon et al. (2003) & $730-870$ & 197 & 74 & 47,7 \\
\hline Sítio Palmital - Viçosa & Ribas et al. (2003) & - & 107 & 51 & 46,8 \\
\hline Fazenda São Geraldo - Viços & Silva et al. (2003) & 670 & 123 & 68 & 56,0 \\
\hline Viçosa & Silva et al. (2004) & - & 124 & 58 & 52,5 \\
\hline Sítio Bom Sucesso - Viçosa & Campos et al. (2006) & 742 & 151 & 59 & 44,5 \\
\hline A.R.Z.M. - Rio Novo & Silva (dados não publicados) & 400 & 97 & 53 & 49,3 \\
\hline
\end{tabular}

R. Árvore, Viçosa-MG, v.31, n.6, p.1121-1130, 2007 
Dentre as espécies listadas nos 15 estudos analisados, Casearia decandra e Guapira opposita merecem destaque pela ocorrência em todos os trabalhos analisados (Tabela 3). As demais espécies que estiveram presentes em pelo menos nove $(60 \%)$ estudos analisados estão descritas na Tabela 3. Dessas, a maioria (15\%) pertencia à família Leguminosae, acompanhada por Annonaceae e Flacourtiaceae, ambas com 10\%, Euphorbiaceae com 8\%, Lauraceae com 7\% e Meliaceae e Rubiaceae com 5\% cada uma, perfazendo $60 \%$ das espécies arroladas, demonstrando a importância dessas famílias nos remanescentes de Florestas Semidecíduas da região (OLIVEIRA-FILHO e FONTES, 2000).

Tabela 3 - Lista contendo as espécies arbóreas mais comumente encontradas em 15 estudos, executados em Viçosa, Ponte Nova, Rio Novo e Juiz de Fora, MG. N = número de registros nos estudos compilados. * = realizam fixação simbiótica de nitrogênio

Table 3 - Tree species more commonly found in fifteen studies carried out in Viçosa, Ponte Nova, Rio Novo and Juiz de Fora, Minas Gerais. N = number of occurrence. $*$ =perform nitrogen symbiotic fixation

\begin{tabular}{cc}
\hline Espécies & $\mathrm{N}$ \\
\hline Casearia decandra Jacq. & 15
\end{tabular}

Guapira opposita (Vell.) Reitz

Apuleia leiocarpa J. F. Macbr.

*Dalbergia nigra Allemão ex Benth.

Jacaranda macrantha Cham.

Matayba elaeagnoides Radlk.

* Piptadenia gonoacantha J.F.Macbr.

Bathysa nicholsonii K.Schum.

Carpotroche brasiliensis (Raddi)

Luehea grandiflora Mart.

Mabea fistulifera Mart.

Ocotea odorifera (Vell.) Rohwer

Sorocea bonplandii (Baill.) Burger, Lanj. et Boer 13

Zanthoxylum rhoifolium Lam. 13

Amaioua guianensis Aubl. $\quad 12$

Casearia arborea Urb. $\quad 12$

Casearia ulmifolia Cambess. $\quad 12$

Erythroxylum pelleterianum A.St.-Hil.. 12

Himatanthus phagedaenicus (Mart.) Woodson 12

Lacistema pubescens Mart. 12

Nectandra lanceolata Nees \& Mart. ex Nees 12

Siparuna guianensis Aubl. $\quad 12$

Vernonia diffusa Less. $\quad 12$

Xylopia sericea A. St.-Hil. $\quad 12$

Alchornea glandulosa Poepp. \& Endl. 11

Allophylus edulis Radlk. ex Warm. 11

Casearia sylvestris Sw. $\quad 11$

Endlicheria paniculata (Spreng.) J.F.Macbr. $-\frac{\text { Spontinua ... }}{11}$

Continued...
Tabela 3 - Cont.

Table 3 - Cont

\begin{tabular}{|c|c|}
\hline Espécies & $\mathrm{N}$ \\
\hline Hortia arborea Engl. & 11 \\
\hline *Machaerium nyctitans (Vell.) Benth. & 11 \\
\hline Maclura tinctoria D.Don ex Steud. & 11 \\
\hline *Pseudopiptadenia contorta (DC.) G.P.Lewis & 11 \\
\hline Rollinia sylvatica (A. St.-Hil.) Mart. & 11 \\
\hline Sparattosperma leucanthum (Vell.) & 11 \\
\hline Tapirira guianensis Aubl. & 11 \\
\hline Alchornea triplinervia Müll.Arg. & 10 \\
\hline Anadenanthera colubrina (Vell.) Brenan & 10 \\
\hline Annona cacans Warm. & 10 \\
\hline Cabralea canjerana (Vell.) Mart. & 10 \\
\hline Campomanesia xanthocarpa Berg & 10 \\
\hline Casearia gossypiosperma Briq. & 10 \\
\hline Cecropia hololeuca Miq. & 10 \\
\hline Copaifera langsdorffii Desf. & 10 \\
\hline Dictyoloma vandellianum A.H.L. Juss. & 10 \\
\hline Guatteria nigrescens Mart. & 10 \\
\hline Guettarda viburnoides Cham. \& Schltdl. & 10 \\
\hline Sapium glandulatum (Vell.) Pax & 10 \\
\hline *Andira fraxinifolia Benth. & 9 \\
\hline Astronium fraxinifolium Schott & 9 \\
\hline Cariniana estrellensis Kuntze & 9 \\
\hline Eriotheca candolleana (K.Schum.) A.Robyns & 9 \\
\hline Eugenia leptoclada Berg & 9 \\
\hline Guatteria villosissima A. St.-Hil. & 9 \\
\hline Inga cylindrica (Vell.) Mart. & 9 \\
\hline Maprounea guianensis Aubl. & 9 \\
\hline Ocotea corymbosa (Meisn.) Mez & 9 \\
\hline Protium warmingianum March. & 9 \\
\hline Rollinia laurifolia Schltdl. & 9 \\
\hline Trichilia catigua A. Juss. & 9 \\
\hline Trichilia pallida $\mathrm{Sw}$ & 9 \\
\hline
\end{tabular}

Casearia decandra, Guapira opposita, Apuleia leiocarpa, Dalbergia nigra, Jacaranda macratha, Matayba elaeagnoides, Piptadenia gonoacantha, Bathysa nicholsonii, Carpotroche brasiliensis, Luehea grandiflora, Mabea fistulifera, Ocotea odorifera, Sorocea bonplandii e Zanthoxylum rhoifolium destacaramse como as espécies mais freqüentemente encontradas nos fragmentos estudados na Zona da Mata (Tabela 3 ) podendo, portanto, ser indicadas como espécies características das Florestas Estacionais Semidecíduas dessa parte do Estado de Minas Gerais.

Essas informações são importantes por apresentarem espécies que caracterizam floristicamente as formações florestais semidecíduas dessa porção do Estado, fornecendo subsídios para trabalhos de seleção e recomendação de uso de espécies florestais para recuperação de áreas degradadas, bem como para planos 
de manejo e conservação de espécies. Adicionalmente, a considerável similaridade florística observada neste estudo e nos demais na Zona da Mata mineira (Tabela 2), a qual ficou acima de $35 \%$ (exceto no estudo realizado em Juiz de Fora), ratifica o uso potencial dessas espécies, uma vez que demonstra a existência de grande afinidade florística entre os fragmentos florestais da região.

Alguns estudos com enfoque na correlação entre variáveis pedológico-topográficas e padrões de distribuição espacial de espécies arbóreas (MARTINS et al., 2003; FERREIRA-JÚNIOR et al., 2007) forneceram informações acerca dos habitats preferenciais de algumas espécies arbóreas, ressaltando o uso potencial de algumas, como Apuleia leiocarpa, Dalbergia nigra, Amaioua guianensis, Luehea grandiflora, Anadenanthera peregrina, Coutarea hexandra e Siparuna guianensis, na recuperação florestal de áreas degradadas, principalmente em encostas e topos de elevações.

Estudos como esses vêm ratificar a afirmação de Oliveira Filho et al. (1994) de que estudos sobre a composição florística e a ecologia de comunidades e populações florestais são essenciais para fundamentar toda e qualquer iniciativa de preservação e conservação de ecossistemas, bem como a identificação de espécies potenciais para recuperação de ambientes degradados. Estudos mais detalhados que tenham como objetivos elucidar e compreender as condições ambientais preferenciais de espécies florestais, como regime de luz e hídrico, perfil nutricional e síndromes de dispersão e polinização, devem ser intensificados, de modo que se consiga um melhor entendimento da auto-ecologia dessas espécies.

\section{REFERÊNCIAS}

ALMEIDA, D. S.; SOUZA, A. L. Florística e estrutura de um fragmento de Floresta Atlântica, no município de Juiz de Fora, Minas Gerais.

Revista Árvore, v.21, n.2, p.221-230, 1997.

AUBRÉVILLE, A. As florestas do Brasil estudo fitogeográfico florestal. Anuário Brasileiro de Economia Florestal, v.11, n.1, p.210-232, 1959.

BRASIL. Ministério da Agricultura, Departamento Nacional de Meteorologia. Normais Climatológicas (1961 - 1990). Brasília: 1992.
BRASIL. Ministério do Meio Ambiente. Fragmentação de ecossistemas causas, efeitos sobre a biodiversidade e recomendações de políticas públicas. Brasília: 2003. 580p.

CAMPOS, E. P. et al. Florística e estrutura horizontal da vegetação arbórea de uma ravina em um fragmento florestal no município de Viçosa - MG. Revista Árvore, v. 30, n.6, p.1045-1054, 2006.

CARNEIRO, P. A. S.; FONTES, M. P. F. Aspectos geográficos e agrícolas do estado de Minas Gerais. In: FONTES, R.; FONTES, M. P. F. (Eds.) Crescimento e desigualdade regional em Minas Gerais. Viçosa, MG: Folha de Viçosa, 2005. p.151-222.

CARVALHO, D. A. et al. Variações florísticas do componente arbóreo de uma floresta ombrófila alto-montana às margens do rio Grande, Bocaina de Minas, MG, Brasil. Acta Botanica Brasílica, v.19, n.1, p.91-109, 2005a.

CARVALHO, D. A. et al. Distribuição de espécies arbóreo-arbustivas ao longo de um gradiente de solos e topografia em um trecho de floresta ripária do rio São Francisco em Três Marias, MG, Brasil.

Revista Brasileira de

Botânica,v.28.n.2,p.329-345, 2005 b.

CASTRO, P. S.; VALENTE, O. F.; COELHO, D. T. Interceptação da chuva por mata natural secundária na região de Viçosa, MG. Revista Árvore, v.7, p.76-88, 1973.

CLINEBELL II, R. R. et al. Prediction of neotropical tree and liana species richness from soil and climate data. Biology Conservation, v.4, p.56-90, 1995.

CRONQUIST, A. An integranted system of classifications of flowering plants. New York: Columbia University Press, 1981. 1262p.

DEAN, W. A ferro e fogo: a história e a devastação da Mata Atlântica Brasileira. São Paulo: Companhia da Letras, 1996. 484p. 
DIAS, A. S. et al. Dinâmica da regeneração natural e a presença de Coffea arabica L. influenciando a diversidade de espécies. (Resumo expandido). In: Avanços nos estudos de ecossistemas terrestres, marinhos e de águas continentais. Anais do VII Congresso de Ecologia do Brasil em Caxambu. Caxambu 2005. (CD de resumos).

DIAS, H. C. T. et al. Variação temporal de nutrientes na serapilheira de um fragmento de Floresta Estacional Semidecidual Montana em Lavras, MG. Cerne,v.8, n.2, p.1-16, 2002.

FARIA, S. M. et al. New nodulating legume trees from south-east Brazil. New Phytologist, v.98, p.317-328, 1984.

FARIA, S. M. et al. Nodulation of legume trees from south-east Brazil. Plant and Soil, v.99, p.347-356, 1987.

FERREIRA-JÚNIOR, W. G. et al. Influence of soils and topographic gradients on tree species distribution in a Brazilian Atlantic Tropical Semideciduous Forest. Edinburgh Journal of Botany, v.64, n.2, p.137-157, 2007.

IRSIGLER, D. T. Composição florística e estrutura de um trecho primitivo de floresta estacional semidecidual em Viçosa, MG. 64f. 2002. Dissertação (Mestrado em Botânica) - Universidade Federal de Viçosa, Viçosa, MG, 2002.

LEITÃO FILHO, H. F. Aspectos taxonômicos das florestas do estado de São Paulo.. In: CONGRESSO NACIONAL SOBRE ESSÊNCIAS NATIVAS, São Paulo,1982. Anais. São Paulo, Instituto Florestal, 1982; Silvicultura em São, v.16, p.197-206, 1982.

LOPES, W. P. et al. Composição da flora arbórea de um trecho de floresta estacional no Jardim Botânico da Universidade Federal de Viçosa (face sudoeste), Viçosa, Minas Gerais. Revista Árvore, v.26, n.3, p.339-347, 2002a.

LOPES, W. P. et al. Estrutura fitossociológica de um trecho de vegetação arbórea no Parque Estadual do Rio Doce - Minas Gerais, Brasil. Acta Botanica Brasílica, v.16, n.4, p.443-456, 2002b.
MARANGON, L. C.; SOARES, J. J.; FELICIANO, A. L. P.. Florística arbórea da Mata da Pedreira, município de Viçosa, Minas Gerais. Revista Árvore, v.27, n.2, p.207-215, 2003.

MARTINS, F. R. Estrutura de uma Floresta Mesófila. Campinas, da Universidade Estadual de Campinas, 1991. 264p.

MARTINS, S. V. et al. Distribuição de espécies arbóreas em um gradiente topográfico de Floresta Estacional Semidecidual em Viçosa, MG.

Scientia Florestalis, v.64, p.172-181, 2003.

MEIRA NETO, J. A. A. et al. Estrutura de uma Floresta Estacional Semidecidual Submontana em área diretamente afetada pela Usina Hidrelétrica de Pilar, Ponte Nova, Zona da Mata de Minas Gerais. Revista Árvore, v.21, n.3, p.337-344, 1997.

MEIRA-NETO, J. A. A.; MARTINS, F. R. Composição florística do estrato herbáceoarbustivo de uma floresta estacional semidecidual em Viçosa - MG. Revista Árvore, v.24,n.4, p.407-416, 2000.

MEIRA NETO, J. A. A.; MARTINS, F. R. Composição florística de uma Floresta Estacional Semidecidual Montana no município de Viçosa MG. Revista Árvore, v.26, n.4, p.437-446, 2002.

MEIRA-NETO, J. A. A.; MARTINS, F. R.; SOUZA, A. L. Influência da cobertura e do solo na composição florística do sub-bosque em uma floresta estacional semidecidual em Viçosa, MG, Brasil. Acta Botanica Brasílica, v.19, n.3, p.473-486, 2005.

MEYER, S. T. et al. Composição florística da vegetação arbórea de um trecho de floresta de galeria do Parque Estadual do Rola-Moça na região metropolitana de Belo Horizonte, MG, Brasil. Acta Botanica Brasílica, v.18, n.4, p.701-709, 2004.

MUELLER-DOMBOIS, D.; ELLENBERG, H.. Aims and methods of vegetation ecology. New York: John Wiley \& Sons, 1974. 547p.

NASCIMENTO, H. E. M. et al. Estrutura e dinâmica de populações arbóreas de um fragmento de floresta estacional semidecidual na região de Piracicaba, SP. Revista Brasileira de Botânica, v.59, n.2, p.329-342, 1999. 
NUNES, Y. R. F. et al. Variação da fisionomia, diversidade e composição de guildas da comunidade arbórea em um fragmento de floresta semidecidual em Lavras, MG. Acta Botânica Brasílica, v.17, n.2, p.213-229, 2003.

OLIVEIRA-FILHO, A. F. et al. Estrutura fitossociológica e variáveis ambientais em um trecho de mata ciliar do córrego dos Vilas Boas, Reserva Biológica de Poço Bonito, Lavras (MG). Revista Brasileira de Botânica, v. 17, p.71-88, 1994.

OLIVEIRA-FILHO, A. T.; FONTES, M. A. L. Patterns of floristic differentiation among Atlantic Forest in southeastern Brazil and the influence of climate. Biotropica v.32, n.4b, p.793-810, 2000.

PEZZOPANE, J. E. M. et al. Aspectos ecofisiológicos de algumas espécies arbóreas em uma floresta estacional semidecidual secundária. Revista Brasileira de Agrometeorologia, v.10, n.2, p.273-281, 2002.

RESENDE, M.; CURI, N.; SANTANA, D. P. Pedologia e fertilidade do solo: interações e interpretações. Brasília: Ministério da Agricultura, 1988.

RIBAS, R. F. et al. Composição florística de dois trechos em diferentes etapas serais de uma floresta estacional semidecidual em Viçosa, Minas Gerais. Revista Árvore, v..27, n.6, p.821-830, 2003

RODRIGUES, L. A. et al. Efeitos de solos e topografia sobre a distribuição de espécies arbóreas em um fragmento de floresta estacional semidecidual, em Luminárias, MG. Revista Árvore, v.31, n.1, p.25-35, 2007.

\section{ROYAL BOTANICAL GARDENS. Index}

Kewensis on compact disc. Oxford: Herbarium of the Royal Botanic Gardens Kew, 1997.

SENRA, L. C. Composição florística e estrutura fitossociológica de um fragmento florestal da Fazenda Rancho Fundo, Viçosa, MG. 2000. 78f. Dissertação (Mestrado em Botânica) Universidade Federal de Viçosa, Viçosa, MG, 2000.
SILVA, A. F. et al. Composição florística e grupos ecofisiológicos das espécies de um trecho de floresta semidecídua submontana da fazenda São Geraldo, Viçosa-MG. Revista Árvore , v.27, n.3, p.311-319, 2003.

SILVA, A. F.; FONTES, N. R. L.; LEITÃO FILHO, H. F. Composição florística e estrutura horizontal do estrato arbóreo de um trecho da Mata da Biologia da Universidade Federal de Viçosa Zona da Mata de Minas Gerais. Revista Árvore, v.24, n.4, p.397-405, 2000.

SILVA, N. R. S. et al. Composição florística e estrutura de uma Floresta Estacional Semidecidual Montana em Viçosa, MG. Revista Árvore, v.28, n.3, p.397-405, 2004.

SILVA-JÚNIOR, W. M. et al. Regeneração natural de espécies arbustivo-arbóreas em dois trechos de Floresta Estacional Semidecidual, Viçosa, MG. Scientia Forestalis, v.66, p.169-179, 2004.

SOARES JÚNIOR, F. J. Composição

florística e estrutura de um fragmento de floresta estacional semidecidual na Fazenda Tico-Tico, Viçosa, MG. 2000. 68f. Dissertação (Mestrado em Botânica) Universidade Federal de Viçosa. Viçosa, MG, 2000.

SOARES, M. P. et al. Composição florística do estrato arbóreo de uma floresta atlântica interiorana em Araponga - Minas Gerais. Revista Árvore, v.30, n.5, p.859-870, 2006.

SOUZA, J. S. et al. Análise das variações florísticas e estruturais da comunidade arbórea de um fragmento de Floresta Semidecídua às margens do rio Capivari, Lavras-MG. Revista Árvore, v.27, n.2, p.185-206, 2003.

TABARELLI, M. ; MANTOVANI, W. Ariqueza de espécies arbóreas na floresta atlântica de encosta no estado de São Paulo (Brasil). Revista Brasileira de Botânica, v.22, n.2, p.217-223, 1999.

VALVERDE, O. Estudo regional da Zona da Mata de Minas Gerais. Revista Brasileira de Geografia, v.20, n.1, p.3-82, 1958. 
VAN DEN BERG, E.; OLIVEIRA-FILHO, A. T.

Composição florística e estrutura fitossociológica de uma floresta ripária em Itutinga, MG, e comparação com outras áreas. Revista Brasileira de Botânica, v.23, n.3, p.231-253, 2000.

VELOSO, H. P.; RANGEL-FILHO, A. L. R.; LIMA, J. C. A. Classificação da vegetação brasileira, adaptada a um sistema universal. Rio de Janeiro: IBGE, Departamento de Recursos Naturais e Estudos Ambientais, 1991.

VIANA, V. M.; TABANEZ, A. J. A.; MARTINEZ, J. L. A. Restauração e manejo de fragmentos florestais. In: CONGRESSO NACIONAL SOBRE ESSÊNCIAS NATIVAS EM CAMPOS DO JORDÃO, 1992, Campos do Jordão.

Anais...Campos do Jordão: Instituto Florestal/ Secretaria de Meio Ambiente, 1992. v.2. p.400-406.
WERNECK, M. S. et al. Florística e estrutura de três trechos de uma floresta semidecídua na Estação Ecológica do Tripuí, Ouro Preto, MG. Revista Brasileira de Botânica, v.23, n.1, p.97-106, 2000.

WERNECK, M. S. et al. Produção de serrapilheira em três trechos de uma floresta semidecídua com diferentes graus de perturbação na Estação Ecológica do Tripuí, Ouro Preto, MG. Revista Brasileira de Botânica v.24, n.2, p.195-198, 2001.

WHITMORE, T. C. Gaps in the forest canopy. In: TOM-LINSON, P. B.; ZIMMERMAN, M.H. (Eds.). Tropical trees as living systems. London: Cambridge University Press, 1978. p.639-655. 
